\title{
White Pine County, NV Public School System Biomass Conversion Heating Project
}

\author{
Award Number DE-FG36-04GO14259
}

\section{Purpose \& Project Information}

The White Pine County School District and the Nevada Division of Forestry agreed to develop a pilot project for Nevada using wood chips to heat the David E. Norman Elementary School in Ely, Nevada. Consideration of the project was triggered by a "Fuels for Schools" grant that was brought to the attention of the School District. The biomass project, that was part of a district-wide energy retrofit, called for the installation of a biomass heating system to be used as the primary heating system for the school while the current fuel oil system remained as back-up. This project was funded by the U.S. Department of Energy as the result of Congressional direction. The system proposed consisted of a biomass steam boiler, storage facility, and an area for unloading and handling equipment necessary to deliver and load fuel. This was the first project of its kind in Nevada. The scope of work for this project was limited to design, purchase, and construction of the system and did not include scope or budget related to the acquisition of fuel, source(s) of the fuel, or the operation of the equipment.

The purpose of the project was to purchase and install a fuel efficient biomass heating system. Additionally, the school district has used information from the operation of the heating system for the following:

1. Demonstration Project: Demonstrate the project and gather data to assist with further research and development of biomass technology; and

2. Education: Educate the White Pine Community and others about biomass and other non fossil fuels

The \$248,000 from the Department of Energy (\$250,000 less \$2,000 for the Congressionally directed deduction) was applied solely toward the purchase and installation of the biomass heating system and facility. Funds from this grant were not used for the demonstration, operation or maintenance of the system, for the procurement or delivery of fuel, or the education of the community.

The system has a heating capacity capable of providing 3 to 4.2 million Btu/hour output capacity in the form of 25 psi steam. The steam supplied by the biomass boiler is piped to the main steam header located in the existing boiler plant. A steam to hot water heat exchanger was installed in the existing steam boiler room and supplies hot water for heating to two separate buildings on campus. The biomass plant has its own proprietary control system that interfaces with a district-wide, electronic mechanical controls system (EMS). The controls pass along various alarms to the control system for notification to remote locations. The system is equipped with diagnostic software that actually calls maintenance personnel to alert them of a problem or potential problem. It also contains a 
fire suppression system that extinguishes the fire in the event the fire extends into the chip delivery area.

The fuel sources for the operation of the system were not addressed by the DOE project.

Although the project does not include the operation of the system, it should be noted that the system is designed to be a clean burning system. Smoke is detectable when the system is brought back on line for the heating season. After the system is on-line, there are no visible emissions. Prior to operation, the District obtained a Class III air quality permit from the Nevada Division of Environmental Protection Bureau of Air Pollution Control. The system will be monitored annually and opacity readings will be taken by qualified personnel or entities.

\section{Fuel Efficiency}

The biomass heating system is a prefabricated 3 MMBTUH (million British thermal units per hour) steam; biomass fueled heating plant that encompasses approximately 36,431 square feet on campus. The biomass heating system, housed in a new building adjacent to the elementary school, was designed to provide an automatic chip delivery system once the chips were delivered into a storage bay. The biomass system ties four separate school buildings and three independent fuel oil heating systems into one heating system and eliminates the need for two fuel oil boilers, which leaves the main fuel oil boiler as a redundant, or back-up, system. Operational savings are expected to be immediately realized from the time required to clean and maintain three boiler systems versus one system.

The following assumptions and estimates were used in the design of the system. The plant will require approximately 150 tons of woody biomass annually. The savings analysis involved a simple spreadsheet analysis for the boilers fuel input, energy output and parasitic electricity consumed. The analysis used outputs from the detailed energy modeling to account for reduction of the heating load from other energy conservation measures (ECMs). This analysis was based on the following assumptions:

$\checkmark$ Fuel energy content was assumed to be 6,600 Btu per pound of wood waste material.

$\checkmark$ The fuel costs included transportation costs only.

$\checkmark$ The motors used 230-volt 3-phase power.

$\checkmark$ The cost of electricity was assumed as \$0.042 per kWh

Based on price and fuel consumption of the biomass versus fuel oil, it was estimated that approximately $\$ 11,987$ in fuel costs would be saved annually given fuel oil prices of $\$ 1.30$ as of March 31, 2004. Fuel oil costs have increased by approximately $50 \%$ since this time so the annual savings should exceed this estimate. 


\title{
Demonstration Project
}

Part of the requirements of being a pilot project was the agreement that the facility be used as a showcase for alternative fuels. The District has increased the awareness of the students and staff as well as the community with respect to alternative fuels, as well as forest health, and hazardous fuel reduction.

The District has hosted a number of tours and has had over 100 individuals tour the facility, observe operations, and listen to the history and purpose of the project. A larger biomass heating project planned for the Nevada Department of Corrections is moving forward due, in part, to a tour and information gathered from the District's pilot project.

\section{Education}

Another component of the pilot project was to integrate into the District's curriculum information about forest health, the biomass project, and alternative fuels. Students of the elementary school where the biomass system is located are required to assist with tours of the biomass heating system. The tours will be designed to inform visitors of the initiative and the scope of this project. The tours will also cover subjects related to the ongoing operation of the project related to the USFS Fuels for Schools program including the source(s) of fuel, hazardous fuel reduction, and alternative fuels. This will help to educate the students about the unique project as well as the visitors.

\section{Summary}

The pilot project has brought a considerable amount of positive attention to White Pine County, White Pine County School District, and the City of Ely. The project is expected to generate annual fuel savings of at least $\$ 12,000$ per year, plus labor efficiency. The facility also consumes wood wastes and should reduce fuel emissions when compared to the fuel oil system. The ecological and financial advantages will be reinforced through the District's educational opportunities and tours of the facility. The successful construction and integration of this alternative fuel heating system will streamline operations and has the potential to tie forest health, fuel reduction, energy production and education together. The project is expected to generate financial savings, demonstrate innovation and efficiency, and help the District reposition funds previously dedicated to operations and maintenance into instructional programs and services.

For more information or questions concerning any of the information contained herein should be addressed to:

\author{
White Pine County School District \\ Paul Johnson, Chief Financial Officer \\ 1135 Avenue C \\ Ely, Nevada 89301
}



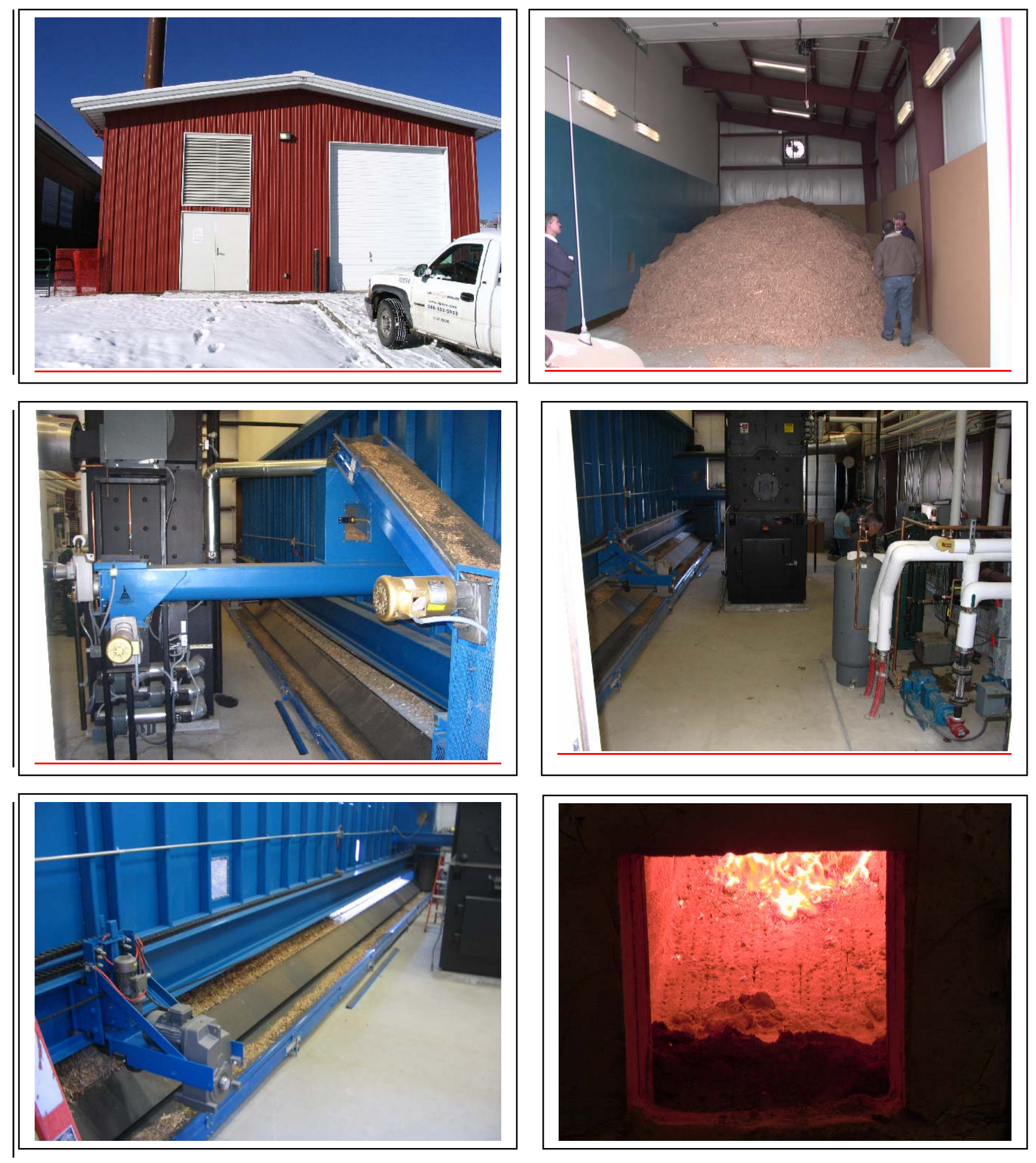


\section{ATTACHMENT A}

\section{Fuels for Schools}

The DOE project scope included only the design and installation of the system. Other funding related to this project came from the "Fuels for Schools" program. The "Fuels for Schools” program is a U.S. Forest Service program that provides funding to states and was designed to help public schools and other public facilities retrofit oil, gas or other heating systems to burn waste wood from hazardous fuels reduction projects. The targeted results of the fuels for school program were to:

- Lower school heating costs

- Provide hands-on resource education in public schools

- Improved forest health

- Reduce fire danger

- Better air quality as efficient boilers reduce slash burning and wildfire

- Lower costs to landowner, as waste becomes a commercially viable product

- Jobs in forests and communities, and

- Reduced reliance on fossil fuels

With the exception of commercial viability of the product, each of the other targeted results was met with the District's biomass heating system project. Because of the unique nature of the wood chips (primarily pinion juniper and cedar trees) and short-term nature of the fuel reduction projects, there has been no other market that has developed.

The District actively participates in National Public Lands day and is a significant factor of the success of this program. With the District's participation, the regional Bureau of Land Management's National Public Lands Day is one of the best attended in the nation. This program provides the District with an opportunity to communicate information about public lands and forest health. 